\title{
To clip or not to clip: still no closure for all
}

\author{
Chelsea Jacobs $^{1}$, Peter V. Draganov ${ }^{2}$, Dennis Yang ${ }^{2}$ \\ ${ }^{1}$ Department of Internal Medicine, University of Florida, Gainesville, FL, USA; ${ }^{2}$ Division of Gastroenterology and Hepatology, Gainesville, FL, USA \\ Correspondence to: Dennis Yang. 1329 SW 16 ${ }^{\text {th }}$ Street, Room \#5252, Gainesville, FL 32608, USA. Email: dennis.yang@medicine.ufl.edu. \\ Provenance: This is an invited article commissioned by our Academic Editor Dr. Jia Zhu (Shenyang Pharmaceutical University, Shenyang, China). \\ Comment on: Feagins LA, Smith AD, Kim D, et al. Efficacy of prophylactic hemoclips in prevention of delayed post-polypectomy bleeding in patients \\ with large colonic polyps. Gastroenterology 2019;157:967-76.e1.
}

Received: 31 August 2019; Accepted: 27 September 2019; Published: 26 November 2019.

doi: $10.21037 / \operatorname{tgh} .2019 .10 .06$

View this article at: http://dx.doi.org/10.21037/tgh.2019.10.06

Colonoscopy reduces both the incidence and mortality associated with colorectal cancer through the early recognition and removal of precancerous adenomatous polyps $(1,2)$. While endoscopic mucosal resection (EMR) has largely replaced surgery as the first-line therapeutic approach for the removal of most colon polyps $(3,4)$, polypectomy can be associated with adverse events, with bleeding being the most commonly encountered (5). Post-polypectomy bleeding can occur either during the procedure or post-operatively. Delayed post-polypectomy bleeding (DPPB), which typically presents within 10 days after resection, has been estimated to occur in the range of $3-12 \%$; depending on several risk factors, including both patient and polyp characteristics (6-11). Prophylactic endoscopic clip closure of the post-resection mucosal defect has been previously proposed to be of benefit, primarily based on findings from retrospective case series (9). More recent higher quality randomized controlled trials have not consistently shown a reduction in DPPB from routine clip closure attempt after EMR; with data suggesting the highest benefit following complete closure and for lesions located in the right colon $(6,12)$. Therefore, whether this practice truly reduces the risk of DPPB remains a topic of debate.

The current study by Feagins et al. is a randomized clinical trial evaluating the efficacy of prophylactic clip placement in the prevention of DPPB after endoscopic resection of colon polyps $\geq 1 \mathrm{~cm}$ in size (13). Patients scheduled to undergo elective colonoscopy were enrolled from 4 Veterans Affairs (VA) Medical Centers during the 7-year study period. Patients were randomized to prophylactic clip placement or no prophylactic clip placement in a 1:1 ratio. The primary outcome was the occurrence of clinically important DPPB, which the authors defined as rectal bleeding within 30 days after polypectomy requiring repeat colonoscopy, associated with hemodynamic instability, requiring blood transfusion or a drop of hemoglobin by $2 \mathrm{~g} / \mathrm{dL}$ or more. The study was designed as an equivalence study, with an estimated required sample size of 1,622 patients, based on an expected DPPB rate set at $1.5 \%$.

A total of 1,098 patients with polyp(s) $\geq 1 \mathrm{~cm}$ were enrolled in the study and randomized to either prophylactic clip placement $(\mathrm{n}=547)$ or no clip placement $(\mathrm{n}=551)$ following polypectomy. The study was terminated prior to reaching the sample size goal of 1,622 due to funding restraints. Final analysis included 680 polyps in 530 in the clip group and 706 polyps in 520 in the no-clip group. There were no significant baseline differences in age, body mass index, gender, procedure indication, or use of antithrombotic agents between the two groups.

Overall, polyp characteristics were similar in patients randomized to clip versus no-clip in terms of morphology or pathology. There were similar numbers of polyps $>2 \mathrm{~cm}$ in both groups (14.9\% clip group vs. $17 \%$ vs. no-clip group, respectively, $\mathrm{P}=0.22)$. Most polyps were removed with hot snare polypectomy ( $97.1 \%$ clip group vs. $96.6 \%$ no-clip group; $\mathrm{P}=0.79)$, and approximately only a one third with an injection-lift technique (32.2\% clip groups vs. $32.7 \%$ no-clip group; $\mathrm{P}=0.75)$. For patients randomized to clip placement, complete closure was achieved in $98.4 \%$ of all cases and $90.3 \%$ of polyps $>2 \mathrm{~cm}$.

In all, Feagins et al. reported important DPPB in 12 of $530(2.3 \%)$ patients randomized to clip placement and 15 of $520(2.9 \%)$ with no clip placement (relative risk $=0.79 ; 95 \%$ 
CI: $0.37-1.66)$. Given the study's early termination due to lack of funding and the higher actual DPPB rates compared to the originally estimated rate set at $1.5 \%$, the study was underpowered and therefore did not meet the a priori equivalence criteria. On multiple logistic regression analysis, significant predictors of DPPB included the use of warfarin with bridging (adjusted OR 7.34; 95\% CI: 2.22-24.3), thienopyridines (adjusted OR 5.79; 95\% CI: 2.25-14.9), larger polyp size $(\mathrm{P}=0.04)$, and proximal polyp location $(\mathrm{P}=0.03)$. Based on their results, the authors concluded that routine clip placement after resection of polyps $\geq 1 \mathrm{~cm}$ does not affect the rate of important DPPB when compared to no clip placement.

Feagins and colleagues should be commended for this study; specifically, for the daunting task of undertaking a randomized trial requiring such a large sample size in an attempt to address a clinically important question: the role of prophylactic clipping after endoscopic resection of polyps $\geq 1 \mathrm{~cm}$ in size. Overall, their results demonstrated that the rate of delayed bleeding in these patients was relatively low, ranging between $2 \%$ to $3 \%$, irrespective of clip placement. However, additional observations beyond this conclusion should be made with caution, as this study was marred by some of the same issues that have yielded conflicting results in prior publications $(9,10,14-18)$. For one, as conceded by the authors, the study was vastly underpowered for equivalence analyses, as they would have needed 2,752 cases for their intention-to-treat evaluation. Hence, demonstration of equivalence between prophylactic clipping vs no clipping on the incidence of DPPB was not achieved, and only suggested by simulated data.

Several additional issues deserve further consideration, many of which are acknowledged and discussed by the authors themselves. It is well recognized that the risk of bleeding is innately different between sessile and pedunculated polyps. Indeed, prophylactic mechanical hemostasis has been shown to be effective in reducing the risk of bleeding in pedunculated polyps $>10 \mathrm{~mm}$ in size, and this practice is currently advocated by GI societal guidelines (19). The impact of polyp morphology on DPPB is unclear and the inclusion of both sessile and pedunculated polyps in this study limits the interpretability of their findings. Another significant limitation of this study was the inclusion of various endoscopic resection techniques (e.g., biopsy forceps, cold or hot snare polypectomy, and EMR) for polyp removal. DPPB has often been attributed to thermal energy induced injury of the underlying resection defect. Hence, submucosal lifting prior to endoscopic resection is recommended for the removal of larger polyps as to minimize deep thermal injury (19). Furthermore, with the increasing number of studies supporting the safety and efficacy of cold snare resection for polyps up to $10 \mathrm{~mm}$, data is also beginning to emerge on the potential role of cold snare resection for larger polyps as well $(20,21)$. Yet, in this study by Feagins et al., most polyps in both groups ( 97\%) were removed with hot snare polypectomy, with lift prior to resection performed in only one third of the patients and cold snare resection in only $2.5 \%$. Lastly, the study did not control and failed to report the electrocautery settings used during polypectomy, a factor that has been shown to impact the risk of DPPB (22).

So should we consider prophylactic clipping after the endoscopic resection of large colon polyps? The answer is it depends. In this particular issue, polyp size does matter. Previous studies have already shown no preventive effect of clip placement following endoscopic resection of polyps $\leq 20 \mathrm{~mm}$ in size $(16,17)$. The prohibitive large number of cases needed for analysis as shown in this trial further emphasizes the low rate of DPPB associated with resection of polyps between $10-20 \mathrm{~mm}$ in size and supports the unlikely benefit of prophylactic clip closure in this cohort. Conversely, clip closure may be indicated in selected cases of non-pedunculated polyps $\geq 20 \mathrm{~mm}$, as a meta-analysis and the two recently published randomized clinical trials have shown a reduction in DPPB rates from $7-12 \%$ to $3-5 \%$ with clip closure $(6,12,23)$. In the North American study (12), the protective effect appeared to be restricted to polyps located in the proximal colon, which is concordant results with prior studies $(10,11)$, including the one by Feagins and colleagues identifying proximal colon location as a predictor for DPPB.

At first glance, the results of these studies would appear to be practice changing; supporting routine clip closure following endoscopic resection of polyps $\geq 20 \mathrm{~mm}$, particularly in the right colon. However, there are also some considerations worthy of discussion. In many cases, clip closure following resection of large lesions can be technically challenging if not impossible even in the hands of expert endoscopists, as shown by the high number of failed closures in these recent studies $(6,12)$. Importantly, additional data is necessary to identify factors associated with failed complete closure, as partial closure may not be effective and possibly even harmful (6,24). Lastly, formal cost-effectiveness analysis is necessary as to better delineate how many clips and in what scenarios this becomes a clinically effective and cost-conscious strategy. 
In summary, at present time, endoscopic clipping should not be routinely recommended following resection of colorectal polyps. Clipping may be considered in selected cases for higher-risk scenarios, such as patients on antithrombotic medications, particularly if such therapy needs to be restarted as soon as possible after EMR. While clip closure may be beneficial following endoscopic resection of selected proximal colon lesions $>20 \mathrm{~mm}$ in size, the decision to proceed mandates a case-by-case assessment of all pertinent endoscopist-, patient-, and proceduralrelated factors.

\section{Acknowledgments}

None.

\section{Footnote}

Conflicts of Interest: PV Draganov is a consultant for Boston Scientific, Cook Medical and Olympus. D Yang is a consultant for Boston Scientific, Lumendi and US Endoscopy. C Jacobs has no conflicts of interest to declare.

Ethical Statement: The authors are accountable for all aspects of the work in ensuring that questions related to the accuracy or integrity of any part of the work are appropriately investigated and resolved.

\section{References}

1. Zauber AG, Winawer SJ, O'Brien MJ, et al. Colonoscopic polypectomy and long-term prevention of colorectalcancer deaths. N Engl J Med 2012;366:687-96.

2. Winawer SJ, Zauber AG, Ho MN, et al. Prevention of colorectal cancer by colonoscopic polypectomy. N Engl J Med 1993;329:1977-81.

3. Jayanna M, Burgess NG, Singh R, et al. Cost Analysis of Endoscopic Mucosal Resection vs Surgery for Large Laterally Spreading Colorectal Lesions. Clin Gastroenterol Hepatol 2016;14:271-8.e1-2.

4. Ahlenstiel G, Hourigan LF, Brown G, et al. Australian Colonic Endoscopic Mucosal Resection (ACE) Study Group. Actual endoscopic versus predicted surgical mortality for treatment of advanced mucosal neoplasia of the colon. Gastrointest Endosc 2014;80:668-76.

5. Rabeneck L, Paszat LF, Hilsden RJ, et al. Bleeding and perforation after outpatient colonoscopy and their risk factors in usual clinical practice. Gastroenterology
2008;135:1899-906.

6. Albéniz E, Álvarez MA, Espinós JC, et al. Clip Closure After Resection of Large Colorectal Lesions with Substantial Risk of Bleeding. Gastroenterology 2019. [Epub ahead of print].

7. Bahin FF, Rasouli KN, Byth K, et al. Prediction of clinically significant bleeding following wide-field endoscopic resection of large sessile and laterally spreading colorectal lesions: A clinical risk score. Am J Gastroenterol 2016;111:1115-22.

8. Moss A, Bourke MJ, Williams SJ, et al. Endoscopic mucosal resection outcomes and prediction of submucosal cancer from advanced colonic mucosal neoplasia. Gastroenterology 2011;140:1909-18.

9. Liaquat H, Rohn E, Rex DK. Prophylactic clip closure reduced the risk of delayed postpolypectomy hemorrhage: experience in 277 clipped large sessile or flat colorectal lesions and 247 control lesions. Gastrointest Endosc 2013;77:401-7.

10. Albéniz E, Fraile M, Ibáñez B, et al. A Scoring System to Determine Risk of Delayed Bleeding after Endoscopic Mucosal Resection of Large Colorectal Lesions. Clin Gastroenterol Hepatol 2016;14:1140-7.

11. Burgess NG, Metz AJ, Williams SJ, et al. Risk factors for intraprocedural and clinically significant delayed bleeding after wide-field endoscopic mucosal resection of large colonic lesions. Clin Gastroenterol Hepatol 2014;12:65161.e1-3.

12. Pohl H, Grimm IS, Moyer MT, et al. Clip Closure Prevents Bleeding After Endoscopic Resection of Large Colon Polyps in a Randomized Trial. Gastroenterology 2019;157:977-84.e3.

13. Feagins LA, Smith AD, Kim D, et al. Efficacy of prophylactic hemoclips in prevention of delayed postpolypectomy bleeding in patients with large colonic polyps. Gastroenterology 2019;157:967-76.e1.

14. Zhang QS, Han B, Xu JH, et al. Clip closure of defect after endoscopic resection in patients with larger colorectal tumors decreased the adverse events. Gastrointest Endosc 2015;82:904-9.

15. Matsumoto M, Kato M, Oba K, et al. Multicenter randomized controlled study to assess the effect of prophylactic clipping on post-polypectomy delayed bleeding. Dig Endosc 2016;28:570-6.

16. Dokoshi T, Fujiya M, Tanaka K, et al. A randomized study on the effectiveness of prophylactic clipping during endoscopic resection of colon polyps for the prevention of delayed bleeding. Biomed Res Int 2015;2015:490272. 
17. Shioji K, Suzuki Y, Kobayashi M, et al. Prophylactic clip application does not decrease delayed bleeding after colonoscopic polypectomy. Gastrointest Endosc 2003;57:691-4.

18. Tominaga N, Tanaka Y, Higuchi T, et al. The effect of hemostasis clipping post endoscopic mucosal resection of colorectal polyps. Gastroenterol Endosc 2014;56:15-20.

19. Ferlitsch M, Moss A, Hassan C, et al. Colorectal polypectomy and endoscopic mucosal resection (EMR): European Society of Gastrointestinal Endoscopy (ESGE) Clinical Guideline. Endoscopy 2017;49:270-97.

20. Kawamura T, Takeuchi Y, Asai S, et al. A comparison of the resection rate for cold and hot snare polypectomy for 4-9 mm colorectal polyps: a multicenter randomized controlled trial (CRESCENT study). Gut 2018;67:1950-7.

21. Choksi N, Elmunzer BJ, Stidham RW, et al. Cold snare

doi: $10.21037 / \operatorname{tgh} .2019 .10 .06$

Cite this article as: Jacobs C, Draganov PV, Yang D. To clip or not to clip: still no closure for all. Transl Gastroenterol Hepatol 2019;4:80. piecemeal resection of colonic and duodenal polyps $\geq 1$ cm. Endosc Int Open 2015;3:E508-13.

22. Watabe H, Yamaji Y, Okamoto M, et al. Risk assessment for delayed hemorrhagic complication of colonic polypectomy: polyp-related factors and patient-related factors. Gastrointest Endosc 2006;64:73-8.

23. Ayoub F, Westerveld DR, Forde JJ, et al. Effect of prophylactic clip placement following endoscopic mucosal resection of large colorectal lesions on delayed polypectomy bleeding: a meta-analysis. World J Gastroenterol 2019;25:2251-63.

24. Feagins LA, Nguyen AD, Iqbal R, et al. The prophylactic placement of hemoclips to prevent delayed postpolypectomy bleeding: An unnecessary practice? A case control study. Dig Dis Sci 2014;59:823-8. 